\title{
SCIDiC
}

\author{
International Journal of Dentistry and Oral Science (IJDOS) \\ ISSN: 2377-8075
}

\section{Role of Dermatoglyphics as a Diagnostic Tool in Syndromes and Systemic Disorders}

Research Article

\section{M.P. Santhosh Kumar*}

Reader, Department of Oral and Maxillofacial Surgery, Saveetha Dental College and Hospital, Saveetha Institute of Medical and Technical Sciences (SIMATS), Saveetha University, 162, Poonamallee High Road, Velappanchavadi, Chennai 600077 Tamil Nadu, India.

\section{Abstract}

Dermatoglyphics is the art and science of the study of surface markings and patterns of ridges on the skin of the fingers, palm, toes and soles. It is a useful tool for investigations into conditions with a suspected genetic basis.Dermatoglyphic patterns on the fingers often differ in syndromes and other systemic conditions with a developmental component, compared to the general population. Current scenario of medical dermatoglyphics is such that the association between fingerprint patterns and various syndromes and systemic disorders such as Down'syndrome, Turner's syndrome, Klinefelter's syndrome, Trisomies 18, 13 and 8, Cri-du-chat Syndrome, Rubinstein-Taybi Syndrome, Cleft lip and palate, Leukemia, Rubella embryopathy, Congenital malformations of the hand and feet and many others has been well established. This article discusses in detail the applications of dermatoglyphics in diagnosing several syndromes and systemic disorders. Dermatoglyphics is an accessible, inexpensive, useful, reliable and noninvasive method of exploring the genetic associations of oral, craniofacial, systemic disorders and syndromes. Thus, apart from personal identification, dermatoglyphics serves as an excellent tool in screening population for several syndromes and systemic disorders.

Keywords: Dermatoglyphics; Finger Prints; Palm Prints; Plantar Study; Syndromes; Down' Syndrome, Dentistry; Systemic Disorders; Genetics; Medicine; Cleft Lip And Palate; Congenital Malformations.

\section{Introduction}

Dermatoglyphics is the science and art of the study of surface markings/patterns of ridges on the skin of the fingers, palm, toes and soles [1]. These dermal ridges over the palms and soles of an individual are unique, universal, inimitable, classifiable, unaltered and are formed by genetic regulation and control during early intrauterine life [2].

The development of dermal ridges starts from 12th-13th week of gestation and by around 20th week, well differentiated recognizable dermal ridges are formed. Fingerprints are classified into three basic types: whorls, loops and arches. As genetic or chromosomal abnormalities might be reflected as alterations in dermal ridges, they can be used as an easily accessible tool in the study of genetically influenced diseases [3].

Dermatoglyphics has many applications in the field of medicine and dentistry to predict several systemic, oral, dental, maxillofacial disorders and syndromic conditions. This is due to the presence of established association between fingerprint patterns; and various syndromic conditions and systemic disorders such as Down's syndrome, Turner's syndrome, Klinefelter's syndrome, Trisomies 18, 13 and 8, Cri-du-chat Syndrome, Rubinstein-Taybi Syndrome, Cleft lip and palate, Leukemia, Rubella embryopathy, Congenital malformations of the hand and feet [4]. Dermatoglyphics are considered as a window of congenital abnormalities and is known to be one of the best available diagnostic tools in genetic disorders.

\section{Dermatoglyphics As A Diagnostic Tool In Syn- dromes}

\section{Down's Syndrome [Trisomy 21]}

Holt, Uchida and Soltan have described the potential of dermato-

*Corresponding Author:

Dr. M.P. Santhosh Kumar M.D.S.,

Reader, Department of Oral and Maxillofacial Surgery, Saveetha Dental College and Hospital, Saveetha Institute of Medical and Technical Sciences (SIMATS), Saveetha University, 162, Poonamallee High Road, Velappanchavadi, Chennai 600077 Tamil Nadu, India.

Tel: 9994892022

Email ID: santhoshsurgeon@gmail.com

Received: April 10, 2021

Accepted: April 29, 2021

Published: May 07, 2021

Citation: M.P. Santhosh Kumar. Role of Dermatoglyphics as a Diagnostic Tool in Syndromes and Systemic Disorders. Int J Dentistry Oral Sci. 2021;08(5):2390-2400. doi: http://dx.doi.org/10.19070/2377-8075-21000470

Copyright: M.P. Santhosh Kumar ${ }^{\circ}$ 2021. This is an open-access article distributed under the terms of the Creative Commons Attribution License, which permits unrestricted use, distribution and reproduction in any medium, provided the original author and source are credited. 
glyphic findings in the clinical diagnosis of autosomal trisomies [5, 6]. Down's syndrome [Trisomy 21 or mongolism] is a syndrome of multiple congenital malformations caused by trisomy of chromosome 21 but about 6 percent of the patients show either a translocation or a mosaic trisomy involving chromosome 21. Patients exhibit flattened face with oblique palpebral fissures, flat occiput, brachycephaly, smallnose, depressed nasal bridge, speckled iris, epicanthal folds, a large furrowed tongue, short and narrow palate, dysplastic ears, shorter neck, limbs and fingers, heart disease, mental retardation, laxity of joint movement and hypotonia.

Cummins et al [7], and Walker et al, [8] demonstrated that dermal configurations can be used for diagnosing down's syndrome. Walker et al [8] used indices in the form of histograms and logarithmic scales to identify 70 percent of patients with down's syndrome. However due to complex analysis involved, this method was not extensively used. Later Reed et al., [9] developed "Dermatoglyphic nomogram" to diagnose down's syndrome which was based on four important areas: the right hallucal, right atd angle, right and left index fingers.

Among the four important dermatoglyphic features considered for Down's syndrome patients, three (axial tri-radius, hallucal pattern, and pattern on the second digit) were used in the nomogram developed by Reed et al [9] and the fourth, the third interdigital pattern, was used in the index created by Walker [10]. Among these four patterns, the arch tibial pattern in the right hallucal area and the distal displacement of the right axial tri-radius showed significant differences between control group and the Down's syndrome group. In both the Caucasian and the Oriental populations these features occurred with a very low frequency in the normal controls.

Uchida et al demonstrated high frequency of arches in fingers and toes among patients with 18 trisomy. About 50 percent of patients exhibited simian creases and lack of loops and whorls. Patients with D 1 trisomy have extreme distal displacement of axial triradius, bilateral simian Creases,and "archfibular- S pattern" [10]. According to Cummins et al [7], a marked increase of ulnar loops on all ten fingertips in both sexes is virtually a constant feature of the dermatoglyphics in Down syndrome. Other dermatoglyphic features are decrease of whorls, arches, radial loops, normal mean $a-b$ ridge count, low TFRC, and increased frequency of hypothenar area patterns. A distally displaced axial triradius, frequently associated with a hypothenar pattern, is a typical dermatoglyphic trait in Down syndrome.

Characteristic dermatoglyphic features of Down syndrome are Ulnar loops considerably increased in frequency, often found on all ten fingertips; Radial loops shifted to fourth and fifth digits; Large hypothenar patterns, predominantly of the ulnar type; Distal axial triradius, high maximal atdangle; Thenar patterns decreased in frequency, size and complexity; 13 patterns increased in frequency; I4 patterns decreased in frequency; Transverse alignment of main lines and ridges in the distal palm (high main-line index); D line terminating in 12 area or even on the radial border of the palm; I4 loop formed by a recurve of the $\mathrm{C}$ line; Absent and abortive $\mathrm{C}$ lines increased in frequency; Single transverse palmar creases increased in frequency; Simian lines increased in frequency; Sydney lines increased in frequency; Single interphalangeal crease on the fifth digit; Fibular loops increased in frequency and whorls decreased in frequency in toes; Arch tibial configura- tion in the hallucal area markedly increased in frequency; Distal loops in the hallucal area mostly small; Distal loops in area IV increased in frequency; Ridge dissociation; and Absence of $\mathrm{Zy}$ godactyloustriradii.

Unlike the palmar pattern intensity, the overall plantar pattern intensity was decreased because of the reduced frequency of patterns in all but the fourth interdigital area. In the fourth interdigital plantar area, distal loops, and therefore the $\mathrm{p}$ " triradii, occurred much more frequently in patients with Down syndrome. The fifth digit is often incurved (clinodactyly) with an especially short middle phalanx which is accompanied by a single digital flexion crease on the palms. On the feet, there is increased space between the first and second toes with a deep plantar furrow [11]. Dermal ridges on the palms and soles of patients with Down syndrome are often badly formed, giving a characteristic appearance of "dotted ridges" or "strings of pearls" (P lines). The degree of ridge malformation varied greatly from very mild cases, with an involvement of small palmar or plantar areas, to severe forms, where most of the ridged skin showed these ill-formed patterns. Utilizing only two dermatoglyphic traits that occurred with high frequency in Down syndrome (transverse alignment of ridges in the distal palmar area and large hypothenar patterns associated with distally displaced axial triradius), Cummins and Platou were able to diagnose correctly almost 90 percent of the individuals determined to have Down syndrome by other clinical means [12]. A particularly simple and rapid test uses a dermatoglyphic nomogram based on the four pattern areas that account for most of the total dermatoglyphic variation between Down syndrome and control subjects. In spite of the high degree of accuracy, dermatoglyphicanalysis can only supplement and not replace more precise means of diagnosis, such as karyotyping.

\section{Trisomy 18}

Patients with trisomy 18 have developmental and mental retardation, Congenital heart defects, elongated skull with a prominent occiput, malformed ears, narrow palatal arch, micrognathia, short neck, short sternum, small pelvis, hypotonia, Inguinal or umbilical hernia, renal malformations, cryptorchidism, flexion deformities of the hands, retroflexible thumb, partial syndactyly of the fingers, hypoplastic Finger and toe nails calcaneovalgus position of feet and short big toe.

A strikingly high frequency of arches on the fingertips and a single flexion crease on the fingers bilaterally, usually the fifth digit, is characteristic of trisomy 18. Majority of the patients have a simian crease, usually bilaterally. Characteristic Dermatoglyphic features of trisomy 18 are: Arches considerably increased in frequency; Radial loops on digits other than second, particularly on the thumb; Decreased frequency of ulnar loops and whorls; Radial exit of main-line A; Distal axial triradius; Increased atd angle; I3 patterns decreased in frequency; I4 patterns decreased in frequency; Ridge dissociation; Single transverse palmar crease increased in frequency; Single flexion crease on the fifth digit; Pattern intensity on soles extremely reduced and Hypoplasia or absence of dermal ridges $[13,14]$.

\section{Trisomy 13}

Characteristic features of trisomy 13 include microcephaly, microphthalmos, cleft lip and cleft palate, low-set and malformed 
ears, capillary hemangiomata, polydactyly, retroflexible thumbs, long hyperconvex nails, and talipes equinovarus. Other clinical findings include those frequently encountered also in trisomy 18 syndrome, such as developmental retardation, failure to thrive, feeding difficulties, hypotonia, jitteriness and apneic spells, ocular hypertelorism, strabismus, epicanthal folds, presumptive deafness, micrognathia, short neck, extra skin on the nape, flexion deformity of fingers, inguinal or umbilical hernia, congenital heart disease, and undescended testes.

Characteristic dermatoglyphic features of trisomy 13 are: Arches increased in frequency; Radial loops frequently on digits other than the second; ulnar loops and whorls decreased in frequency; 13 patterns increased in frequency; I4 patterns decreased in frequency; Axial triradius extremely distal; very wide atd angle; Thenar patterns increased in frequency; Triradiusa displaced radially; a-b ridge count increased; Radial exit of mainline A; Single transverse flexion crease markedly increased in frequency; Arch fibular and arch fibular S pattern frequent; and Ridge dissociation. Pattern intensity was increased in palms and the intensity of plantar patterns was greatly reduced $[15,16]$.

\section{Trisomy 8 Mosaicism}

Individuals with trisomy 8 mosaicism have psychomotor retardation; an elongated and slender trunk with narrow shoulders and pelvis; a large and prominent forehead; strabismus; agenesis of the corpus callosum; abnormal nose; malformed ears; micrognathia; short neck; restricted articular function; bone dysplasia, extra ribs and vertebrae; hypertonicity; deep palmar and plantar creases; nail dysplasia; absent patellae; heart defects; renal anomalies; and frequent upper respiratory infections.

Characteristic Dermatoglyphic features of trisomy 8 mosaicism are: Arches increased in frequency in fingertips; Whorls decreased in frequency but often present on the same hand together with arches; ulnar loops decreased in frequency; low TFRC; Thenar patterns increased in frequency; Hypothenar patterns increased in frequency; 12 patterns increased in frequency; 13 patterns increased in frequency. I4 patterns increased in frequency; Single transverse palmar crease increased in frequency; Arches on great toes increased in frequency; Whorls in the hallucal area increased in frequency; Plantar pattern intensity considerably increased; and Deep furrows on palms and soles [17].

Pattern intensity on both the palms and the soles was very high and the high plantar pattern intensity may be a characteristic feature only of trisomy 8 . In patients with trisomies 13,18 , and 21, the pattern intensity on the soles was found to be markedly decreased. Deep palmar and plantar skin furrows represent a distinct feature of trisomy 8 [18].

\section{Turner's Syndrome}

Abnormalities of the sex chromosomes do not have as much influence on ridge formation as do autosomal chromosomal aberrations. Nevertheless, there are some noteworthy dermatoglyphic features associated with sex chromosome defects.

Turner syndrome is caused by full or partial monosomy of an $\mathrm{X}$ chromosome, with or without mosaicism. Characteristic features in this syndrome are short stature, ptosis, epicanthal folds, cataracts, and strabismus, depressed corners of the mouth, high arched and narrow hard palate, micrognathia, malocclusion, prominent ears, coarctation of the Aorta, low posterior hairline, short metacarpal bones [particularly the fourth and fifth], narrow fingernails and toenails, cubitus valgus, osteoporosis, multiple pigmented, lack of pubertal sexual development, undeveloped breasts, infantile external genitalia, primary amenorrhea, horseshoe kidney, and multiple intestinal telangiectases. Palmar skin is often very thin and wrinkled, and there is presence of prominent palmar volar pads.

Characteristic dermatoglyphic features are: increseda-b ridge count; increased TFRC; increased frequency of patterns in both the third and fourth interdigital areas; increased hypothenar pattern, distally displaced axial triradius, increased maximal atdangle, full or a transitional single transverse crease in palms, missing digital $\mathrm{c}$ triradius and a main-line A termination in the thenar area, large whorls and large distal loops in the hallucal areas of the feet [19].

Dallapiccolaet al. identified five dermatoglyphic characteristics (TFRC, a-b ridge count, maximal atdangle, $\mathrm{T}$ line terminating in the second interdigital area, and presence of hypothenar patterns on the palms) and four skeletal characteristics (carpal sign, metacarpal sign, phalangeal sign, and abnormally shaped distal phalanges), to diagnose a patient with Turner's syndrome [20].

\section{Klinefelter's Syndrome}

According to Cushman and Soltan, patients with 47, XXY Klinefelter'ssyndrome exhibited significantly lower mean total ridge count [21]. It is also been shown that the addition of $\mathrm{X}$ and $\mathrm{Y}$ chromosomes progressively reduces the total ridge count.

47, XXY Klinefelter Syndrome: The clinical features of this syndrome are frequent gynecomastia, sparse facial hair, female pubic escutcheon, and disturbances of sexual function. Characteristic dermatoglyphic features are lower TFRC, lower ulnar loop ridge count, increased width of the ridges, increased frequency of arch patterns on fingertips, reduced a-b ridge count, distal axial triradius, and significant reduction of pattern intensity on the soles [21].

48, XXYY Klinefelter Syndrome: Patients with this syndrome are taller, aggressive and mentally retarded. Dermatoglyphic features are low TFRC, increased frequency of fingertip arches, distally displaced axial triradius, and normal mean maximal atdangle. It is considered that the presence of three hypothenar patternsloop carpal, loop radial, and arch radial-associated with an ulnar triradius to be characteristic of the XXYY variant of Klinefelter syndrome [22].

48, XXXY; 49, XXXYY; 49, XXXXYK linefelter Syndrome: Characteristic features of this syndrome are poor development of the external genitalia and more severe mental retardation. Dermatoglyphic features are: increased arches on the fingertips, reduced mean TFRC, Abortive $\mathrm{C}$ main lines, and ulnar triradius on the palm, associated with a radial loop. A single transverse palmar crease was a frequent finding in various variants of the Klinefelter syndrome [23].

46, XX Klinefelter Syndrome: Males with this syndrome have small testes, small penis and scrotum, gynecomastia and lack of 
facial hair, and normal Intelligence. Dermatoglyphic features are: increased frequency of fingertip arches, slightly decreased mean TFRC, distally displaced triradii, and normal mean atdangle [24].

\section{Polysomies of the Y Chromosome}

47, XYY Syndrome: Patients with this syndrome exhibit muscle weakness, poor coordination, mild mental retardation, normal sexual development and are usually excessively tall. Characteristic dermatoglyphic features are: low mean TFRC; normal mean atdangle; distal displacement of the axial triradius; and decreased frequency of the palmar patterns [25].

48, XYYY: Apart from low TFRC, no unusual dermatoglyphic features have been noted in this condition [26].

\section{Polysomies of the X Chromosome}

Patients with this condition exhibit congenital anomalies, menstrual disorders, amenorrhea, sterility, and mental retardation. Characteristic dermatoglyphics features are lower mean TFRC correlated with an increasing number of $\mathrm{X}$ chromosomes and abnormal frequencies of the fingertip patterns [27].

\section{Triploidy}

Common features of individuals with chromosomal triploidy are premature birth with very low birth weight, developmental retardation, extremely low viability, cutaneous syndactyly of the third and fourth fingers, coloboma of the iris, hypospadias, and testicular germinal cell hypoplasia. Characteristic dermatologic features are: presence of single transverse palmar crease, increased frequency of whorls and decreased frequency of ulnar loops in the fingertips, increased frequency of radial loops shifting from their usual site on the second digit to the third, fourth, and fifth digit and missing or fused digital triradii [28]. Butler et al., [29] observed bilateral absence of distal flexion creases on the second, third, and fourth digits and two unusually close proximal creases on the fifth digits in a case of 69, XXX triploidy.

\section{Cri-Du-Chat Syndrome}

This syndrome occurs due to deletion of The Short Arm of Chromosome 5. The most characteristic feature of this syndrome is a peculiar, high-pitched cry of infants resembling the mewing of a kitten. The patients exhibit Low birth weight, failure to thrive, respiratory stridor, laryngomalacia, profound mental retardation, microcephaly, hypertelorism, strabismus, broad based nose, oblique palpebral fissures, epicanthal folds, low-set ears, micrognathia. premature greying of the hair, various skeletal anomalies, and muscular hypotonia [30].

Characteristic dermatoglyphic features are: increase in frequency of whorls; decrease in frequency of ulnar loops; Distal axial triradius; increase of the maximal mean atdangle Thenar patterns somewhat increased in frequency; Hypothenar patterns decreased in Frequency; I4 patterns increased in frequency and patterns result mostly from the $\mathrm{D}$ line; slight decrease in frequency of $\mathrm{I} 3$ patterns; Main-line $\mathrm{C}$ usually exits on the ulnar border of the palm; Interdigital triradiusbc; and Single transverse flexion crease increased in frequency. According to Warburton and Miller, unlike controls, where the most frequent terminations of the $\mathrm{C}$ line are in the third or fourth interdigital areas of the palms, the usual termination of the $\mathrm{C}$ line in patients with the $5 \mathrm{p}$ - syndrome was the ulnar border of the palm. Partial syndactyly of the fingers or toes is relatively frequent among patients with the cri-du-chat syndrome. In the hallucal area, an increased frequency of distally oriented loops was observed, whereas whorls, tibial loops, and arches were somewhat decreased in frequency [31].

\section{Wolf-Hirschhorn Syndrome}

This syndrome occurs due to deletion of The Short Arm of Chromosome 4. Patients with this syndrome share many clinical features in common with patients having the cri-du-chat syndrome such as low birth weight, mental deficiency, growth retardation, microcephaly, hypertelorism, strabismus, epicanthal folds, a broad-based nose, micrognathia, muscular hypotonia, carp like mouth, cleft or high-arched palate, beaky nose, preauricular dimple, hypospadias, delay in ossification of pelvic and carpal bones, seizures, deformed ears, sacral dimple, foot deformities, prominent glabella, cryptorchidism, haemangioma of the forehead, midline scalp defect, and coloboma of the iris or retina [32].

Characteristic Dermatoglyphic features of the $4 \mathrm{p}$ - syndrome are: Arches significantly increased in frequency; decrease in frequency of whorls and ulnar loops; low TFRC; Whorls significantly decreased in frequency; Association of Wdl on thumb and A on the second and third digits; Axial triradius somewhat distal ( $\left.\mathrm{t}^{\prime}\right)$; Thenar patterns somewhat increased in frequency; Hypothenar patterns decreased in frequency; 13 patterns decreased in frequency; I4 patterns increased in frequency; Single transverse flexion crease increased in frequency; and Ridge dissociation [33].

According to Warburton there was an association of a double loop on the thumb and arches on the second and third fingers in patients with this syndrome. In contrast to the cri-du-chat syndrome patients, the majority of patients with the Wolf-Hirschhorn syndrome showed an exit of main-line $\mathrm{C}$ in the 13 or 14 areas rather than on the ulnar border of the palm.

Perhaps the most striking dermatoglyphic trait of the $4 \mathrm{p}$ - patients is ridge dissociation [34]. The dermatoglyphics in both WolfHirschhorn syndrome and cri-du-chat syndrome showed an increase of pattern frequency in the thenar and 14 areas, a decrease of patterns in the hypothenar area, elevated axial triradii, and a high proportion of palms with a simian crease. However, the frequency of both single transverse palmar creases and distally displaced axial triradii was much higher in the cri-du-chat syndrome than in the Wolf-Hirschhorn syndrome. Dermatoglyphic traits that differentiate $4 \mathrm{p}$ - from $5 \mathrm{p}$ - include an increased frequency of the fingertip arches, low TFRC, 'and ridge hypoplasia, whereas a high frequency of the fourth interdigital loops resulting from main-line $\mathrm{D}$, and a high frequency of ulnar exits of main-line $\mathrm{C}$ are seen in $5 \mathrm{p}$ - and not in $4 \mathrm{p}$ - syndrome.

\section{Deletions of Chromosome 18}

Deletion of The Short Arm of Chromosome 18 (18p-): The patients have low birth weight, somatic growth retardation, Mental retardation, hypertelorism, strabismus, epicanthal folds, ptosis of the eyelids, flattened or broad nasal bridge, large ears, micrognathic mandible, dental caries, webbing of the neck, lymphedema, shield chest, hands are usually stubby with short fingers, and par- 
tial syndactyly of the toes.

Characteristic Dermatoglyphic features of the different deletions of chromosome 18 are: Whorls increased in frequency; Ulnar loops, arches, radial loops decreased in frequency; higher TFRC; Distal axial triradius; Thenar patterns decreased in frequency; I3 patterns increased in frequency; decrease of 14 patterns; Hypothenar patterns decreased in frequency; Missing ctriradius; and Single transverse palmar crease increased in frequency. Plantar dermatoglyphics revealed bilateral whorls in the hallucal areas and bilateral fibular loops on the great toes of patients [35].

Deletion of The Long Arm of Chromosome 18 (L8q-): 18q - syndrome is associated with characteristic clinical findings, such as low birth weight, mild microcephaly, profound mental retardation, retarded somatic growth, short stature, frequent hypotonia, seizures, midfacial dysplasia, glaucoma, strabismus, nystagmus, tapetoretinal degeneration, optic atrophy, short nose, mouth carp, abnormal pinna, atresia of ear canals, conspicuous subacromial dimples, long, tapering fingers, clubfoot, congenital heart defect, hypoplastic genitalia.

The most striking dermatoglyphic features in this syndrome are increase in the frequency of composite whorls on the fingertips, decrease in frequency of arches, ulnar loops, and radial loops, elevated Mean TFRC values, low mean a-b ridge count, increase in the mean atdangle, distal displacement of axial triradii, usually into the t' position, widened atdangle, increased pattern intensity on the palms in the thenar, hypothenar areas and, especially, the in the third interdigital area, and single transverse palmar creases in palms [36].

Ring Chromosome 18 (18r): Patients with 18r syndrome exhibit clinical features of both 18 pand $18 \mathrm{q}$ - syndrome, such as low birth weight, short stature, microcephaly, motor and mental retardation, hypotonia, congenital heart defects, midfacial dysplasia, strabismus, hypertelorism, epicanthus, ptosis, carp-shaped mouth, micrognathia, anomalies of pinnae, ear canal stenosis, short neck, and skeletal anomalies.

Dermatoglyphic features of 18r syndrome are: increase of whorls on the fingertips, distally displaced axial triradii, increase in the pattern frequency in the thenar/first interdigital area, and the third interdigital area, and presence of a single transverse palmar crease.

The hallucal area exhibited predominantly the loop distal pattern and most of the great toes showed loop fibular pattern [37].

\section{De Lange Syndrome}

Individuals with the de Lange syndrome show mental and growth retardation, low birth weight, generalized hirsutism, synophrys, long eyelashes, anteverted nostrils, microcephaly, protruding philtrum, thin lips, oligodactyly or peromelia, limitation in extension of the elbows, proximally placed thumbs, clinodactyly of fifth fingers, webbing of second and third toes, cardiac defects, undescended testes, delayed eruption and wide spacing of teeth [38].

Characteristic Dermatoglyphic features of the de Lange Syndrome are: Radial loops increased in frequency, often found on digits other than the second (particularly on the third); Whorls markedly decreased in frequency; Distal axial Triradius; wider atd angle; low TFRC; Thenar patterns increased in frequency; Interdigital triradiusbe; 13 loops increased in frequency; Transverse or oblique loop in the I4 area; True or transitional single transverse palmar crease increased in Frequency; presence of simian crease bilaterally; Single flexion crease occasionally present on the fifth digit and presence of Ridge dissociation [39].

\section{Rubinstein-Taybi Syndrome}

The Rubinstein-Taybi syndrome includes developmental retardation, broad terminal phalanges of thumbs and halluces, prominent forehead, antimongoloid slant of the palpebral fissures, strabismus, epicanthal folds, heavy or high-arched eyebrows, long eyelashes, lid ptosis, abnormal ears and nose, broad nasal bridge, high-arched palate, mild retrognathia, Grimacing, Clinodactyly of the fifth fingers, overlapping toes, Angulation deformity of the thumbs and halluces with abnormal shape of the proximal phalanx, and duplicated distal or proximal phalanx of the hallux [40].

Characteristic Dermatoglyphic features of the Rubinstein- Taybi syndrome are: Arches increased in frequency; Radial loops shifted to fingers other than the second; ulnar loops and whorls decreased in frequency; Additional apical triradius on the thumb or great toe; Double patterns on the thumbs; Thenar/I1 patterns increased in frequency, size, and complexity; Ulnar loop is a predominant pattern in the hypothenar area; Distal axial triradius (and therefore an increased maximal atdangle); 12 patterns increased in frequency; 13 patterns increased in frequency; Missing c triradius; Single transverse palmar crease increased in frequency; Distorted, unusually long distal loop in hallucal area; distal loops increased in frequency; Combination of two loops in the hallucal area; and Deep plantar crease in the first interdigital plantar area [41].

\section{Smith-Lemli-Opitz Syndrome}

The characteristic features of the Smith-Lemli-Opitz syndrome include moderate to severe mental retardation, growth retardation of prenatal onset, microcephaly, ptosis of eyelids, inner epicanthal folds, internal strabismus, short nose with broad nasal tip and anteverted nostrils, increased nasolabial distance, broad maxillary alveolar ridges, mild micrognathia, low-set ears, short neck, short stature, narrow shoulders, cutaneous syndactyly of the second and third toes, cryptorchidism, hypospadias, changes in muscle tone, shrill cry, cleft palate or bifid uvula, metatarsus adductus, deep sacral dimple, pyloric stenosis, and cardiac anomalies [42].

Characteristic dermatoglyphic features are: Decreased frequency of ulnar loops; increased frequency of arches and whorls; Low TFRC; Decreased frequency of patterns in the hypothenar, third, and fourth interdigital areas in palm; increased frequency of thenar patterns; distally displaced axial triradius; true or transitional simian crease on the palm bilaterally; hypoplasia of dermal ridges; and missing triradius c bilaterally [43].

Because ridge differentiation is closely associated with embryogenesis of the limbs, the most obviously abnormal dermatoglyphics can be expected to be found in individuals with congenitally malformed hands and feet. All anomalous extremities show an unusual epidermalridge arrangement with the magnitude of ridge abnormality roughly proportional to the skeletal defects. 


\section{Thalidomide Embryopathy}

Thalidomide is an agent which affects limb development. The most striking dermatoglyphic findings in thalidomide damaged infants were absence of the axial triradii accompanied by transverse flow of the palmar ridges, shifted and doubled digital triradii, abnormal course of the main lines, ridge dissociation, abnormal palmar flexion creases, missing thenar crease and single transverse creases [44].

\section{Hypoplasia of The Thumbs}

Absent or hypoplastic thumbs occur occasionally as isolated anomalies but usually they are associated with other congenital malformations and syndromes, such as Holt-Oram syndrome, thalidomide embryopathy, Fanconi's anaemia, trisomy 18, and ring-D chromosome. In this condition, the ridge configurations in the proximal palm are distorted, the ridges run transversely across the palm, and axial tri-radius and the thenar crease are missing. Presence or absence of an extra digital tri-radius and the main line originating from it indicates whether the triphalangeal thumb is indeed a thumb or a duplicated index finger associated with absence of the thumb [45].

\section{Triphalangy of The Thumbs}

The triphalangeal thumb is usually thin and finger-like and is frequently displaced distally to the level of other digits. It is found in conditions such as Holt-Oram syndrome, thalidomide embryopathy, congenital hypoplastic anaemia, and trisomy 13. In this condition, the epidermal ridges tend to be transversely aligned across the palm, the axial Tri-radii are either absent or displaced distally and radially and there is presence of single transverse palmar creases. Radial loops, rarely found on digits other than the second in normal individuals, have been reported on the triphalangeal thumbs [46].

\section{Holt-Oram Syndrome}

Holt-Oram syndrome is a disorder consisting of skeletal anomalies like hypoplastic, triphalangeal, missing thumbs, hypoplasia of the radius or peromelia, hypoplasia of the clavicles and narrow shoulders. This syndrome also manifests cardiovascular defects, like atrial and ventricular septal defects. The characteristic dermatoglyphic findings in this condition are axial triradii that are missing or distally and radially shifted, a missing or rudimentary thenar crease, and transversely oriented epidermal ridges on the palms, increased whorls, decreased ulnar loops, and increased total finger ridge count [TFRC]. Most of the palms of affected individuals showed abnormal distal palmar creases, mostly a single transverse crease in its full or transitional forms [47].

\section{Anonychia}

Anonychia is characterized by complete absence of the nail on the index and middle fingers, presence of minute portions of the thumbnail, a less diminished nail on the ring finger and normal nail of the little finger. Anonychia can be associated with ectrodactyly, syndactyly, or polydactyly. Anonychia on the toes parallels the anonychia of corresponding fingers. With absence or hypoplasia of the nails, the ridges extend over the dorsal area normally covered by the nail. A similar extension of the ridges is found in apical dystrophy (brachydactyly type B) and in the nail-patella syndrome (onycho-osteodysplasia) [48].

\section{Distal Phalangeal Hypoplasia}

Hypoplasia of the distal phalanges is associated with brachydactyly, onycho-osteodystrophy, pseudohypoparathyroidism (Albright osteodystrophy), the hand-foot-uterus syndrome, and Sorsby syndrome (macula coloboma and brachydactyly). A common dermatoglyphic finding in patients with distal phalangeal hypoplasia is a high proportion of arches on all fingertips and toes. Loops and whorl patterns were either low or absent [49].

\section{Brachydactyly}

Brachydactyly is a condition characterized by reduced length of the fingers and toes because of shortening of any of their bony components, the metacarpals or phalanges. There are several types of brachydactyly like type A, B, C, D and E. Penrose and Holt have described the abnormal dermatoglyphic features in patients with brachydactyly type A [50]. In the study by Hoefnagel and Gerald, most of the patterns in the brachydactylous individuals were arches, radial loops, low mean TFRC, high mean atd angle and high mean $\mathrm{a}-\mathrm{b}$ ridge count whereas ulnar loops were markedly diminished in frequency and no whorls were found. On the feet, the persons with brachydactyly showed an increased number of whorls on the toes and tibial loops on the great toe [51]. An increased frequency of fingertip arches was observed in a family with the hand-foot-uterus syndrome by Halal et al [52]. On the basis of dermatoglyphics alone, the researchers could distinguish between the affected and unaffected individual.

Type B brachydactyly [ectrodactyly or apical dystrophy] in association with syndactyly, is called as symbrachydactyly. The fingertip patterns are displaced to the extreme end of the finger in concentric circles, with no triradii. The broadened thumbs may have an apical triradius at the tip, which is similar to the findings in the Rubinstein-Taybi syndrome [53]. In the study by Degenhardt and Geipel [54], there was an increase in both arches and whorls on the fingertips, and decrease in the ulnar loops among the affected members. In another study by Fuhrmann et al.,[55] an increased number of fingertip whorls and a high TFRC were found in a proband and his affected mother. Battle et at., [56] reported high frequency of thenar/first interdigital patterns among patients with broad or bifid thumbs, an association observed also in the Rubinstein-Taybi syndrome. According to Robinson et al [57] in Brachydactyly type $\mathrm{C}$, there were four radial loops on fingers other than the second (three on the third and one on the fourth) and increased thenar/I patterns.

\section{Pseudohypoparathyroidism}

Pseudohypoparathyroidism (Albright osteodystrophy) resembles brachydactyly type E. The characteristic dermatoglyphic features in this condition are increased fingertip arches, and hypothenar Patterns, presence of Distal axial tri-radii and the mean atdangle of $55^{\circ}$ [58].

\section{Camptodactyly}

Camptodactyly is a condition of permanent flexion of one or 
both interphalangeal joints.

Goodman et al reported that the affected siblings had many fingertip whorls that extended distally on the terminal phalanges, whereas the tri-radii of these whorls were on the middle or even proximal portions of the digits. Characteristic dermatoglyphic findings are increased TFRC, increased $a-b$ ridge count, increased atdangles, absence of digital creases over the permanently flexed joints on the fingers and toes, multiple secondary creases on the palms and soles and increased number of whorls on the toes of the patients [59].

\section{Syndactyly}

Syndactyly can be found as an isolated congenital malformation or as a part of another syndrome, such as Apert syndrome (acrocephalosyndactyly type I), Carpenter syndrome (acrocephalopolysyndactyly), de Lange syndrome, oculodentoosseous syndrome, oral-facial-digital syndrome, and Smith-LemIi-Opitz syndrome. The palmar area proximal to the webbing between the digits is covered with transversely aligned ridges and an interdigital triradius generally underlies the web. In cases of zygodactyly of the third and fourth fingers, the usual triradii $b$ and $c$ are missing and are replaced by an interdigital triradiusbc. The interdigital triradius may be shifted distally in severe degrees of webbing. The fingertip patterns vary with the degree of syndactyly. Because the interdigital triradii indicate a close developmental relationship between adjacent digits, presence of such a triradius can be considered as a minor manifestation of zygodactyly [60].

\section{Polydactyly}

Extra digits on the hand or foot are associated with dermatoglyphic aberrations. A well-developed supernumerary digit has its own fingertip pattern and an imperfectly developed extra digit or a digit joined to its neighbour has a pattern different from the adjacent digit. A completely duplicated and separated extra digit tends to have the same type of pattern as the digit it duplicates. An extra digital tri-radius is generally found at the base of the supernumerary digit and constitutes a significant feature of polydactyly [61].

Because epidermal ridges reflect the embryonic development of the hands and feet, such gross malformations of the distal parts of the limbs as ectrodactyly or peromelia are accompanied by obvious dermatoglyphic aberrations. The extent of dermatoglyphic alterations can be great, depending on the severity of the hand or foot malformations. Usual dermatoglyphic features, such as digital triradii and interdigital patterns, may be so disturbed that they cannot be identified. The lower limb malformations consist of coexistent osseous syndactyly, polydactyly, and brachydactyly. In spite of the abnormal epidermal configurations, ridge directions conform to the anomalous moulding of the hand and foot structures $[62,63]$.

Dermatoglyphics generally do not play an important part in clinical diagnosis of hand and foot abnormalities as these can be more precisely identified by other means such as an x-ray examination. However, understanding the relationship between embryonic development and ridge formation is necessary for a meaningful interpretation of the significance of dermatoglyphics in limb malformations and these relationships may apply to other medi- cal disorders as well. Use of dermatoglyphics to diagnose hand and foot malformations may reveal even minor abnormalities that may otherwise escape attention.

\section{Dermatoglyphics As A Diagnostic Tool In Sys- temic Disorders.}

\section{Cleft Lip and Cleft Palate}

Oral clefts are among the common congenital birth defects with a broad phenotypic gamut. Since the epidermal ridges of the fingers and palms as well as the facial structures like lip, alveolus, and palate are formed from the same embryonic tissues during the same embryonic period, the genetic and environmental factors responsible forcausing cleft lip and palate might also affect dermatoglyphic patterns. Hence,several studies weredone to compare the dermatoglyphic pattern of children with orofacial clefts and normal children and to determine the correlation of dermatoglyphics with orofacial clefts.

Silver [64] investigated the fingertips, third interdigital area, and hallucal patterns of cleft lip and palate patients and found no significant difference in any dermatoglyphic configurations between patients and controls. Silver [64] concluded that "cleft lip/ palate is a congenital anomaly whose developmental basis seems to be independent of the production of aberrant dermatoglyphic patterns," Similarly, de Bie and Matton [65] found no significant differences in dermatoglyphic patterns between cleft lip/ palate patients and controls. Adams and Niswander [66] studied only the atdangle in patients with cleft lip, with or without cleft palate $(\mathrm{CL} \pm \mathrm{P})$ and observed an increased asymmetry of atdangles in the group of patients with familial CL - $t$ - P. In the study by Wittwer [67], several atypically located triradii, duplications of triradii, and a tendency of the palmar main lines toward a vertical alignment was noted among patients with cleft lip and palate.

In the study by Dziuba [68], the frequencies of thenar and first interdigital area patterns were increased on the left palms in patients of both sexes. Male patients exhibited low TFRC; increased frequency of ulnar loops and arches; decreased frequency of whorls. Female patients had a lower frequency of the patterns in the fourth interdigital area of the left hand.

Piatkowska and Sokolowski compared dermatoglyphic features of primary and secondary palate. They concluded that in primary palate patients, a significant decrease of patterns in the fourth interdigital area, particularly peripheral loops and in secondary palate patients a significant decrease of tented loops in the third interdigital area was found [69].

Neiswanger et al in their study did not find any significant pattern count differences between cleft and non-cleft individuals, but observed increased pattern dissimilarity in individuals with clefts, compared to both their unaffected relatives and controls. They concluded that increased dermatoglyphic pattern dissimilarity in individuals with non-syndromic orofacial clefts may reflect a generalized developmental instability [70]. According to Harika et al significant difference was observed between parents with cleft children and parents with at least 2 healthy children with reference to pattern types; TRC and a-b ridge count and atd angle. Absence of t point was variably noticed in the mothers of affected children 
[71]. According to Mayall et alno statistically significant difference was found in the dermatoglyphic pattern and atd angle for both cleft children and Non cleft children [72].

Saujanya et al conducted a study to determine the relative risk of cleft lip and palate on the basis of lip prints and dermatoglyphics, as genetic background may be useful for genetic counseling, and the development of future preventive measures. 31 parents of children with cleft lip/palate as a study group, and 31 parents of unaffected children as control group were included. They concluded that among the mothers of the study group, type $\mathrm{O}$ followed by type IIa lip patterns were found to be significantly higher in upper and lower lips, and in fathers type IIa followed by type $\mathrm{O}$ were significantly higher. In the control group, type IIb followed by type III were higher in both fathers and mothers. Dermatoglyphic analysis of palm and finger prints revealed no significant difference in the pattern types and total ridge counts, but the Atd angle asymmetry was found to be significant between study and control group [73]. Maheshwari et al reported that the most frequently seen dermatoglyphic trait in the cleft and healthy group was loops followed by whorls and arches. A highly significant difference between loops in the cleft and healthy group and statistically significant difference in the whorls were found [74].

Eslami et al investigated if Iranian individuals with nonfamilial cleft lip and palate (CLP) and their unaffected parents displayed more dermatoglyphic asymmetry than the normal population. Results revealed no significant differences between the study and control groups in terms of their asymmetry of atd angle, a-b ridge count, and pattern dissimilarity score. However, significant differences in mean TRC between CLP patients and control children were found for the right ring digit, right little digit, and left index digit. Also, there were significant differences among CLP patients and control children as well as unaffected fathers of CLP patients and their control group in terms of type of finger print pattern. No enhanced fluctuating asymmetry was found in most of the dermatoglyphic traits in the population studied, which indicated a low degree of developmental instability of the sporadic cases of cleft deformity [75]. Saxena et al compared the dermatoglyphic patterns in subjects with clefts and controls and both their parents to study the genetic etiology. Increased frequency of loops and arches and low mean total ridge count was observed in cleft subjects. Increased frequency of loops and arches with decreased frequency of whorls, mean total ridge count, and atd angle of right hand was found in parents of cleft group as compared with the parents of the controls [76].

Mathew et al collected dermatoglyphic data from 50 oral cleft children and 50 normal children and analysed. They found an increase in the ulnar loop patterns on the distal phalanges of the ten fingers, an increase in the atd angle and an increase in the fluctuating asymmetry of the atd angle in the oral cleft children, which indicates the degree of developmental instability of the oral cleft individual [77]. Balgir evaluated dermatoglyphic characteristics of sixty-nine cases of cleft lip with or without cleft palate and twenty-eight isolated cleft palate cases for digital patterns, interdigital patterns, palmar simian crease and sydney line, and model types of C- and D-line terminations. Increased frequency of ulnar and radial loops than the arches and whorls was observed in cleft lip with or without cleft palate patients compared to controls. Interdigital patterns were less frequent in cleft lip and cleft palate patients. Simian crease and Sydney line were more common in patients than in controls. Model types of C- and D-line terminations showed variations in patients and controls. Wider 'atd' angle and dermatoglyphic asymmetry were noted in the patient groups. These findings suggested the dichotomy or heterogeneity of cleft lip and cleft palate anomalies. Thus,dermatoglyphics can be used as tool to study the developmental instability of cleft anomalies and provides data to assess the genetic etiology of clefting [78].

\section{Cerebral Gigantism}

Cerebral gigantism is characterized by excessive length at birth, rapid linear growth in the first years of life, advanced bone age, large head, frontal bossing, prognathism, large hands and feet, poor coordination, clumsiness, and mild mental retardation.Characteristic dermatoglyphic features are: increased TFRC; both high and normal a-b ridge count; decreased distance between palmar triradii band c; increase in the mean ridge breadth; tendency toward vertical or horizontal alignment of palmar ridges, increase in unusual exit of main-line $\mathrm{A}$ in the thenar area; wide separation of triradiia and b; Bilateral simian creases and lower main-line index [79].

\section{Rubella Embryopathy}

Children affected showed a variety of severe congenital anomalies, including microcephaly, cataracts, heart defects,mental retardation and abnormal dermatoglyphics.

Achset al found an increased frequency of simian lines, distally displaced axial triradii, and radial loops on other than second digits in both rubella-damagedand rubella-exposed groups of children [80]. Alter and Schulenberg observed several unusual dermatoglyphic traits in patients with rubella embryopathy like increased frequency of transitional andfull simian palmar creases, an increased frequency of whorls on thefingertips [especially in males], a decreased a-b ridge count, an increased atd angle, anda tendency toward more patterns in the interdigital areas, thenar/ first interdigital area, and hypothenar area [81].

In the study on children with congenital rubella, the fingertip whorlswere found to be significantly increased with a predominance for females and increase in both simian and Sydney creases [82]. In another study, only Sydney creases wereelevated among adult patients with rubella embryopathy, whereasthe frequency of simian creases was found to be normal. It was postulated that the teratogenic effects of the rubella virus mayoverride otherwise normal lateral differences of dermatoglyphictraits during development and influence the patterns towards greatersymmetry [83]. According to PurvisSmith and Menser, an excess of whorls was found in patients of both sexes [especially in males] than either their mothers or fathers, and the high whorl frequency was attributed to direct teratogenesis. The authors concluded that although both genetic factors and theviral influence accounted for the very high whorl frequency in rubella-affected individuals, the teratogenic effect of the virus appeared to predominate [84].

\section{Leukemia}

Aleksandrowiczet al. reportedan increased frequency of fingertip radial loops in males andof "radial whorls" in females with leukemia [85]. 
Acute Lymphocytic Leukemia: Colombo et al. found whorls to be decreased and ulnarloops to be increased in females [86]. Purvis-Smith and Menser found a higher frequency of whorls in patients of both sexes and the fathers of the male patients and an increase ofsingle transverse creases together with Sydney lines in female patientsand their mothers [87]. However, in the Werteleckiet al. series, the fathers and thebrothers both had a lower frequency of whorls than the male patients.An increase of Sydney lines withoutan increase of single transverse creases was observed in severalinvestigated groups of patients [88]. In the Colombo et al. study, the increasein frequency of the Sydney line was limited to male patients [86].

Acute Myelogenous Leukemia: Rosner reported increased radial loops on the right hand of malesand, in females, there was an increased atdangle and a higher frequencyof hypothenar patterns of the left palms [89].

Acute Leukemia (Not Otherwise Designated): Verbov reported an increase of whorls and a decrease inulnar loops in the males with acute leukemia [91]. Menser and PurvisSmithfound a decreased frequency of ulnar loops and an increased frequency of arches on the fingertips of male children.They also found an increase of fingertipwhorls and a decrease of arches in female children with acute leukemia [87].

Acute Blast Cell Leukemia: Menser and Purvis-Smith reported an increase of arches, decrease of ulnar loops in the fingertips, and significantly increased frequency of Sydney lines in patientswith acute blast cell leukemia [91].

Chronic Lymphocytic Leukemia: Rosnerfound increased frequencies of fingertip arches and hypothenar patterns on the right palms, wider atdangles, and a decreased frequency of 14 patterns among female patients with chronic lymphocytic leukemia [89]. Aleksandrowiczet al.found an increase of the fingertip radial loops in males andof the "radial whorls" in females [85]. Verbov observed an increasedfrequency of radial loops and a decrease of fingertip archesin males whereas females had an increased frequency of fingertiparches [90].

Chronic Myelogenous Leukemia: An increased frequency of whorls and a decreased frequency ofulnar loops on the fingertips of the patients was reported by Rosner [89].

\section{Cytomegalic Inclusion Disease}

Wright et al. [92] and Purvis-Smith et al [93] found an increase in the frequency of whorl patterns in infants with cytomegalic inclusion disease and in their fathers. On the palms, simian line and transitionaltransverse creases were found. It was concluded that genetic factors controlling immune responses may beinherited from the father and predispose a particular foetus to damagefrom certain viral infections. Dermatoglyphic changes can be a sensitive indicator of this damage.

\section{Celiac Disease}

Celiac disease is a disorder characterized by malabsorption, abnormalsmall bowel structure, and intolerance to gluten. According to David et al [94], dermatoglyphicchanges in adult patients with celiac disease varied between moderate epidermal ridge at- rophy associatedwith the appearance of white lines and actual loss of visibleridges and disappearance of white lines. Ridge atrophy improved with a gluten-freediet and dermatoglyphicscould be employed as an indicator of the patients' responseto the diet therapy.In contrary, the studies by McCrae et al. [95] and Mylotte et al [96] revealed no abnormal dermatoglyphics in patients with celiac disease compared to controls and concluded that dermatoglyphics cannot be utilized for diagnosing celiac disease. Although the authors suggested that ridgeatrophy in an adult should alert the possibility ofceliac sprue, they did not find dermatoglyphic analysis to be a reliable method of monitoring the response of the celiac patient to thegluten-restricted diet.

\section{Conclusion}

Dermatoglyphics definitely have a scientific basis for their role as a genetic marker in various syndromic conditions and systemic disorders. By understanding the relationship between medical disorders and dermatoglyphic variations, it can serve as an excellent, non-invasive tool in the diagnosis of several systemic conditions. Dermatoglyphics is an accessible, inexpensive, useful, reliable and noninvasive method of exploring the genetic associations of oral, craniofacial, systemic disorders and syndromes. Thus, apart from personal identification, dermatoglyphics serves as an excellent tool in screening population for several syndromes and systemic disorders.

\section{References}

[1]. Cummins C, Midlo C. Fingerprints, palms and soles- finger prints, palms and soles: An introduction to dermatoglyphics. Philadelphia: Blakinston Company. 1943; 11-15.

[2]. Galton F. Finger prints. London: Macmillan publishers. 1892;3-5.

[3]. Campbell ED. Fingerprints and palmer Dermatoglyphics. E-fingerprints. net. 1998.

[4]. Schaumann B, Alter M. "Dermatoglyphics in Medical disorders." (1976): $1-258$.

[5]. HOLT SB. Finger-print patterns in mongolism. Annals of human genetics. 1963 Mar;27(3):279-82.

[6]. Uchida IA, Soltan HC. Dermatoglyphics in medical genetics. Endocrine and genetic diseases of childhood. 1969:579-92.

[7]. Cummins H. Dermatoglyphic stigmata in mongoloid imbeciles. The Anatomical Record. 1939 Apr;73(4):407-15.

[8]. WALKER NF. The use of dermal configurations in the diagnosis of mongolism. J Pediatr. 1957 Jan;50(1):19-26. Pubmed PMID: 13377275.

[9]. Reed TE, Borgaonkar DS, Conneally PM, Yu P, Nance WE, Christian JC. Dermatoglyphic nomogram for the diagnosis of Down's syndrome. J Pediatr. 1970 Dec;77(6):1024-32. Pubmed PMID: 4249677.

[10]. UCHIDA IA, PATAU K, SMITH DW. Dermal patterns of 18 and D1 trisomics. Am J Hum Genet. 1962 Dec;14(4):345-52. Pubmed PMID: 13995080.

[11]. Penrose LS. THE CREASES ON THE MINIMAL DIGIT IN MONGOLISM. The Lancet. 1931 Sep 12;218(5637):585-6.

[12]. CUMMINS H, PLATOU RV. Mongolism; an objective early sign. South Med J. 1946 Dec;39(12):925-8. Pubmed PMID: 20274932

[13]. Penrose LS. Dermatoglyphics in trisomy 17 or 18. J Ment Defic Res. 1969 Mar;13(1):44-59. Pubmed PMID: 4238320.

[14]. Ross LJ. Dermatoglyphic observations in a patient with trisomy 18. J Pediatr. 1968 Jun;72(6):862-3. Pubmed PMID: 5652615.

[15]. Magenis RE, Hecht F, Milham S Jr. Trisomy 13 (D1) syndrome: studies on parental age, sex ratio, and survival. J Pediatr. 1968 Aug;73(2):222-8. Pubmed PMID: 5668372.

[16]. Taylor MB, Juberg RC, Jones B, Johnson WA. Chromosomal variability in the D1 trisomy syndrome. Three cases and review of the literature. Am J Dis Child. 1970 Oct;120(4):374-81. Pubmed PMID: 4250203.

[17]. Schaumann B. Dermatoglyphics in trisomy 8 mosaicism. Humangenetik. 1974;24(3):201-5. Pubmed PMID: 4442867.

[18]. Tuncbilek E, Halicioglu C, Say B. Trisomy-8 syndrome. Humangenetik. 1974 Jun 26;23(1):23-9. Pubmed PMID: 4847188. 
[19]. HOLT SB, LINDSTEN J. DERMATOGLYPHIC ANOMALIES IN TURNER'S SYNDROME. Ann Hum Genet. 1964 Sep;28:87-100. Pubmed PMID: 14204855 .

[20]. Dallapiccola B, Bagni B, Pistocchi G. Dermatoglyphic and Skeletal Hand Abnormalities in Turner's Syndrome-A Tentative Scoring Method 1. Acta geneticae medicae et gemellologiae: twin research. 1972 Apr;21(1-2):69-78.

[21]. Cushman CJ, Soltan HC. Dermatoglyphics in Klinefelter's syndrome (47,XXY). Hum Hered. 1969;19(6):641-53. Pubmed PMID: 5399260

[22]. Alter M, Gorlin R, Yunis J, Peagler F, Bruhl H. Dermatoglyphics in XXYY Klinefelter's syndrome. Am J Hum Genet. 1966 Nov;18(6):507-13. Pubmed PMID: 5927873.

[23]. FERGUSON-SMITH MA, JOHNSTON AW, HANDMAKER SD. Primary amentia and micro-orchidism associated with an XXXY sex-chromosome constitution. Lancet. 1960 Jul 23;2(7143):184-7. Pubmed PMID: 13822249.

[24]. Nicolis GL, Hsu LY, Sabetghadam R, Kardon NB, Chernay PR, Mathur DP, et al. Klinefelter's syndrome in identical twins with the 46,XX chromosome constitution. Am J Med. 1972 Apr;52(4):482-91. Pubmed PMID: 5017243.

[25]. Mavalwala J, Thompson H, Parker C, Wilson G. Sole dermatoglyphics of XYY patients. Am J Phys Anthropol. 1970 Jan;32(1):145-6. Pubmed PMID: 5415583.

[26]. Schoepflin GS, Centerwall WR. 48,XYYY: a new syndrome? J Med Genet. 1972 Sep;9(3):356-60. Pubmed PMID: 4116771.

[27]. Sokolowski J, Knaus A, Kleczkowska A. Dermatoglyphics of two cases of X tetrasomy. Am J Hum Genet. 1969 Nov;21(6):559-65. Pubmed PMID: 5365758.

[28]. Penrose LS. Dermatoglyphs in human polyploidy. J Med Genet. 1968 Mar;5(1):1-3. Pubmed PMID: 5653863.

[29]. Butler LJ, Chantler C, France NE, Keith CG. A liveborn infant with complete triploidy (69,XXX). J Med Genet. 1969 Dec;6(4):413-21. Pubmed PMID: 4312483.

[30]. Milunsky A, Chitham RG. The cri du chat syndrome. Journal of Intellectual Disability Research. 1966 Jun;10(2):153-7.

[31]. WARBURTON D, Miller OJ. Dermatoglyphic features of patients with a partial short arm deletion of a B-group chromosome. Annals of Human Genetics. 1967 Nov;31(2):189-207.

[32]. Leão JC, Bargman GJ, Neu RL, Kajii T, Gardner LI. New syndrome associated with partial deletion of short arms of chromosome No. 4. Clinical manifestations of hypospadias, beaked nose, abnormal iris, hemangioma of forehead, seizures, and other anomalies. JAMA. 1967 Oct 30;202(5):434-7. Pubmed PMID: 6072506.

[33]. Carter R, Baker E, Hayman D. Congenital malformations associated with a ring 4 chromosome. J Med Genet. 1969 Jun;6(2):224-7. Pubmed PMID: 5801472 .

[34]. Warburton D. Comments on dermatoglyphics. Birth Defects. 1969;5(3):123-4.

[35]. Jacobsen P, Mikkelsen M. The 18p- syndrome. Report of two cases. Ann Genet. 1968 Dec;11(4):211-6. Pubmed PMID: 5306362

[36]. Mavalwala J, Wilson MG, Parker CE. The dermatoglyphics of the 18qsyndrome. Am J Phys Anthropol. 1970 May;32(3):443-9. Pubmed PMID: 5419379.

[37]. Palmer CG, Fareed N, Merritt AD. Ring chromosome 18 in a patient with multiple anomalies. J Med Genet. 1967 Jun;4(2):117-23. Pubmed PMID: 5619991.

[38]. Pearce PM, Pitt DB. Six cases of de Lange's syndrome; parental consanguinity in two. Med J Aust. 1967 Mar 11;1(10):502-6. Pubmed PMID: 6022911.

[39]. Salazar FN. Dermatological manifestations of the Cornelia de Lange syndrome. Arch Dermatol. 1966 Jul;94(1):38-43. Pubmed PMID: 5939543.

[40]. Filippi G. The Rubinstein-Taybi syndrome. Report of 7 cases. Clin Genet. 1972;3(5):303-18. Pubmed PMID: 4628491

[41]. Simpson NE, Brissenden JE. The Bubinstein-Taybi syndrome: familial and dermatoglyphic data. Am J Hum Genet. 1973 May;25(3):225-9. Pubmed PMID: 4704855.

[42]. Fried K, Fraser WI. Smith-Lemli-Opitz syndrome in an adult. Journal of Intellectual Disability Research. 1972 Mar;16(1-2):30-4.

[43]. SMITH DW, LEMLI L, OPITZ JM. A NEWLY RECOGNIZED SYNDROME OF MULTIPLE CONGENITAL ANOMALIES. J Pediatr. 1964 Feb;64:210-7. Pubmed PMID: 14119520.

[44]. Giroux J, Miller JR. Dermatoglyphics of the broad thumb and great toe syndrome. Am J Dis Child. 1967 Feb;113(2):207-9. Pubmed PMID: 6019436.

[45]. Hermann J. A familial dysmorphogenic syndrome of limb deformities, characteristic facial appearance and associated anomalies: The" pseudothalidomide" or" SC" syndrome. BD: OAS. 1969;5:81-9.

[46]. Murphy S, Lubin B. Triphalangeal thumbs and congenital erythroid hypoplasia: report of a case with unusual features. J Pediatr. 1972 Nov;81(5):987-
9. Pubmed PMID: 5086730.

[47]. Chang CH. Holt-oram syndrome. Radiology. 1967 Mar;88(3):479-83.

[48]. Holt SB. The effect of absence of thumb on palmar dermatoglyphics. J Med Genet. 1972 Dec;9(4):448-50. Pubmed PMID: 4646554

[49]. Robinow M, Johnson GF. Dermatoglyphics in distal phalangeal hypoplasia. Am J Dis Child. 1972 Dec;124(6):860-3. Pubmed PMID: 4639222.

[50]. Penrose LS, Holt SB. Note on dermatoglyphic data in a brachydactylous family. Ann Hum Genet. 1966 May;29(4):383-8. Pubmed PMID: 5961826.

[51]. Hoefnagel D, Gerald PS. Hereditary brachydactyly. Ann Hum Genet. 1966 May;29(4):377-82. Pubmed PMID: 5961825.

[52]. Halal F. The hand-foot-genital (hand-foot-uterus) syndrome: family report and update. Am J Med Genet. 1988 Jul;30(3):793-803. Pubmed PMID: 3189398.

[53]. Freire-Maia N, Maia NA, Pacheco CN. Mohr-Wriedt (A2) brachydactyly: analysis of a large Brazilian kindred. Hum Hered. 1980;30(4):225-31. Pubmed PMID: 7390514.

[54]. Degenhardt KH, Geipel G. Dominant erbliche Perodaktylien in 4 generationen einer Sippe. Z. menschl. Vererb.-u. Konstitutionslehre. 1954;32:227307.

[55]. Fuhrmann W, Steffens C, Schwarz G, Wagner A. Dominant crbliche Brachydaktylie mit Gelenksaplasien. Humangenetik. 1965 Jan 1;1(4):337-53.

[56]. Battle HI, Walker NF, Thompson MW. Mackinder's hereditary brachydactyly: phenotypic, radiological, dermatoglyphic and genetic observations in an Ontario family. Ann Hum Genet. 1973 Apr;36(4):415-24. Pubmed PMID: 4748760

[57]. Robinson GC, Wood BJ, Miller JR, Baillie J. Hereditary brachydactyly and hip disease. Unusual radiological and dermatoglyphic findings in a kindred. J Pediatr. 1968 Apr;72(4):539-43. Pubmed PMID: 5647298.

[58]. FORBES AP. FINGERPRINTS AND PALM PRINTS (DERMATOGLYPHICS) AND PALMAR-FLEXION CREASES IN GONADAL DYSGENESIS, PSEUDOHYPOPARATHYROIDISM AND KLINEFELTER'S SYNDROME. N Engl J Med. 1964 Jun 11;270:1268-77. Pubmed PMID: 14133664

[59]. Goodman RM, Katznelson MB, Manor E. Camptodactyly: occurrence in two new genetic syndromes and its relationship to other syndromes. J Med Genet. 1972 Jun;9(2):203-12. Pubmed PMID: 5046631.

[60]. Grebe H. Studies of papillary line changes in syndactyly and polydactyly. Journal of Morphology and Anthropology. 1940 Jan 1(H. 1):62-78.

[61]. Cummins H, Sicomo J. PLANTAR EPIDERMAL CONFIGURATIONS IN LOW-GRADE SYNDACTYLISM (ZYGODACTYLY) OF. The Anatomical Record. 1923;25(6):355.

[62]. Aase JM, Smith DW. Congenital anemia and triphalangeal thumbs: a new syndrome. J Pediatr. 1969 Mar;74(3):471-4. Pubmed PMID: 5764780

[63]. Elçioglu N, Atasu M, Cenani A. Dermatoglyphics in patients with CenaniLenz type syndactyly: studies in a new case. Am J Med Genet. 1997 Jun 27;70(4):341-5. Pubmed PMID: 9182770.

[64]. Silver WE. Dermatoglyphics and cleft lip and palate. Cleft Palate J. 1966 Oct;3:368-75. Pubmed PMID: 5222744.

[65]. De Bie S, Hayashi M, Matton MT, Matton G, Vrijdagh S, Lejour M, et al. Dermatoglyphic analysis of primary and secondary cleft palate patients. Cleft Palate J. 1977 Jul;14(3):222-5. Pubmed PMID: 267521.

[66]. Adams MS, Niswander JD. Developmental 'noise' and a congenital malformation. Genet Res. 1967 Dec;10(3):313-7. Pubmed PMID: 5587946.

[67]. Wittwer B. Dermatoglyphics in cheilognathopalatoschisis. The Lancet. 1967 Sep 16;290(7516):617

[68]. Dziuba P. Badania nad dermatoglifami dłoni i stóp u pacjentów z rozszczepam wargi górnej, wyrostka zebodołowego i podniebienia [Studies on palm and sole dermatoglyphics in patients with clefts of upper lip, alveolar process and palate]. Czas Stomatol. 1972 Dec;25(12):1195-200. Polish. Pubmed PMID: 4509459.

[69]. Piatkowska E, Sokolowski J. Letter: Dermatoglyphs in primary and secondary cleft palate. Am J Hum Genet. 1973 Sep;25(5):575-6. Pubmed PMID: 4741851 .

[70]. Neiswanger K, Mukhopadhyay N, Rajagopalan S, Leslie EJ, Sanchez $\mathrm{CA}$, Hecht JT, et al. Individuals with nonsyndromic orofacial clefts have increased asymmetry of fingerprint patterns. PLoS One. $2020 \mathrm{Mar}$ 20;15(3):e0230534. Pubmed PMID: 32196525.

[71]. Harika DJ, Sridevi E, Sai Sankar AJ, Pranitha K, Gosla SR, Kiran GB. Dermatoglyphic Analysis in Parents with Cleft Children: A Comparative Study. Contemp Clin Dent. 2018 Sep;9(Suppl 2):S291-S298. Pubmed PMID: 30294160.

[72]. S Mayall S, Chaudhary S, Kaur H, Manuja N, Ravishankar T, A Sinha A. Comparison of Dermatoglyphic Pattern among Cleft and Noncleft Children: A Cross-sectional Study. Int J Clin Pediatr Dent. 2017 JulSep;10(3):245-249. Pubmed PMID: 29104383.

[73]. Saujanya K, Prasad MG, Sushma B, Kumar JR, Reddy YS, Niranjani K. 
Cheiloscopy and dermatoglyphics as genetic markers in the transmission of cleft lip and palate: A case-control study. J Indian Soc Pedod Prev Dent. 2016 Jan-Mar;34(1):48-54. Pubmed PMID: 26838148.

[74]. Maheshwari N, Bansal K, Rao DJ, Chopra R. Comparison of dermatoglyphic traits and dental anomalies associated with cleft lip or cleft lip and palate patients with normal healthy children. J Indian Soc Pedod Prev Dent. 2013 Oct-Dec;31(4):260-4. Pubmed PMID: 24262401.

[75]. Eslami N, Jahanbin A, Ezzati A. Palm and finger print characteristics in nonfamilial cleft lip and palate patients and their parents. J Craniofac Surg. 2013 May;24(3):769-72. Pubmed PMID: 23714876.

[76]. Saxena RS, David MP, Indira AP. Dermatoglyphic evaluation in subjects and parents of cleft lip with and without cleft palate. Cleft Palate Craniofac J. 2013 Nov;50(6):e105-10. Pubmed PMID: 22906393.

[77]. Mathew L, Hegde AM, Rai K. Dermatoglyphic peculiarities in children with oral clefts. J Indian Soc Pedod Prev Dent. 2005 Oct-Dec;23(4):179-82. Pubmed PMID: 16327138.

[78]. Balgir RS. Dermatoglyphics in cleft lip and cleft palate anomalies. Indian Pediatr. 1993 Mar;30(3):341-6. Pubmed PMID: 8365784.

[79]. Milunsky A, Cowie VA, Donoghue EC. Cerebral gigantism in childhood. A report of two cases and a review of the literature. Pediatrics. 1967 Sep;40(3):395-402. Pubmed PMID: 5298529.

[80]. Achs R, Harper RG, Siegel M. Unusual dermatoglyphic findings associated with rubella embryopathy. N Engl J Med. 1966 Jan 20;274(3):148-50. Pubmed PMID: 5322927.

[81]. Alter M, Schulenberg R. Dermatoglyphics in the rubella syndrome. JAMA. 1966 Aug 29;197(9):685-8. Pubmed PMID: 5952909.

[82]. Hook EB, Achs RS, Harper R. An investigation of dermatoglyphic asymmetry in rubella embryopathy. Teratology. 1971 Nov;4(4):405-8. Pubmed PMID: 5116885.

[83]. Purvis-Smith SG, Howard PR, Menser MA. Dermatoglyphic defects and rubella teratogenesis. JAMA. 1969 Sep 22;209(12):1865-8.

[84]. Purvis-Smith SG, Menser MA. Dermatoglyphics in adults with congenital rubella. Lancet. 1968 Jul 20;2(7560):141-3. Pubmed PMID: 4173264.
[85]. Aleksandrowicz J, Schiffer Z, Debski T. Dermatoglyphics in leukaemia. The Lancet. 1966 Dec 17;288(7477):1364.

[86]. Colombo A, Gasparoni MC, Biscatti G, Severi F. Dermatoglifi e leucemia linfatica acuta nell'infanzia [Dermatoglyphics and acute lymphatic leukemia in childhood]. Minerva Pediatr. 1973 Mar 10;25(8):335-7. Italian. Pubmed PMID: 4515149.

[87]. Purvis-Smith SG, Menser MA. Dermatoglyphics in children with acute leukaemia. Br Med J. 1973 Dec 15;4(5893):646-8. Pubmed PMID: 4519014

[88]. Wertelecki W, Plato CC, Fraumeni JF Jr. Dermatoglyphics in leukaemia. Lancet. 1969 Oct 11;2(7624):806-7. Pubmed PMID: 4186056.

[89]. Rosner F. Dermatoglyphics of leukaemic children. Lancet. 1969 Aug 2;2(7614):272-3. Pubmed PMID: 4184135.

[90]. Verbov JL. Dermatoglyphs in leukaemia. J Med Genet. 1970 Jun;7(2):12531. Pubmed PMID: 5519597.

[91]. Menser MA, Purvis-Smith SG. Dermatoglyphics in leukaemia. Lancet. 1972 Apr 29;1(7757):956-7. Pubmed PMID: 4112118.

[92]. Wright HT Jr, Parker CE, Mavalwala J. Unusual dermatoglyphic findings associated with cytomegalic inclusion disease of infancy. A first report and practical review. Calif Med. 1972 Mar;116(3):14-20. Pubmed PMID: 4335498.

[93]. Purvis-Smith SG, Hayes K, Menser MA. Dermatoglyphics in children with prenatal cytomegalovirus infection. Lancet. 1972 Nov 4;2(7784):976-7. Pubmed PMID: 4116858.

[94]. David TJ, Ajdukiewicz AB, Read AE. Dermal and epidermal ridge atrophy in celiac sprue. Gastroenterology. 1973 Apr;64(4):539-44. Pubmed PMID: 4700769.

[95]. McCrae WM, Sandor G, Sangani AP, Stalker R. Fingerprint changes in coeliac disease. Br Med J. 1971 Jul 10;3(5766):109-10. Pubmed PMID: 5090799.

[96]. Mylotte M, Egan-Mitchell B, Fottrell PF, McNicholl B, McCarthy CF. Fingerprints in patients with coeliac disease and their relatives. Br Med J. 1972 Oct 21;4(5833):144-6. Pubmed PMID: 5078446. 